\title{
Наближений спосіб розрахунку розмахів вільних коливавнь квазілінійного дисипативного осцилятора
}

\author{
В.П. Ольшанський, О.І. Спольнік, В.В. Бурлака, М.В. Сліпченко \\ Харківський національний технічний університет сільського господарства \\ імені Петра Василенка (м. Харків, Україна) \\ email:1 OlshanskiyVP@gmail.com, ${ }^{2}$ alexspo@ukr.net, ${ }^{3}$ Burlaka2V@ukr.net, \\ 4 Slipchenko_M@ukr.net ORCID: ${ }^{1}$ 0000-0003-1407-4476, ${ }^{2}$ 0000-0002-4389-8813, \\ ${ }^{3}$ 0000-0001-9437-1950, ${ }^{4}$ 000-0002-9728-661X
}

\begin{abstract}
Викладено спрощений спосіб наближеного обчислення розмахів вільних затухаючих коливань осцилятора зі слабкою степеневою нелінійністю у виразі сили пружності. В основу запропонованого способу покладено припущення, що нелінійний доданок у виразі сили пружності мало впливає на рівняння обвідної графіка вільних коливань. Використане тут рівняння обвідної, за прийнятим припущенням, відповідає першому наближенню асимптотичного методу теорії нелінійних коливань і було одержане при дослідженні вільних коливань дисипативного осцилятора Дуффінга в роботах інших авторів. Але тут додатково враховано залежність тривалостей напівциклів від змінної амплітуди коливань, що властиво нелінійним системам. За виведеними фрормулами проведено розрахунки розмахів коливань в умовах дії різних сил опору, а саме: сухого тертя Кулона, лінійного в'язкого тертя та квадратичного в'язкого опору. Розглянуто різні варіанти степеневих нелінійностей, що доповнюють лінійну складову в виразі сили пружності. 3 метою з'ясування похибок наближеного способу, проведено чисельне комп'ютерне інтегрування диференціального рівняння руху при різних видах опору. За підсумком порівняння числових результатів, одержаних різними способами, встановлено такі обмеження на нелінійність сили пружності, коли похибки наближених компактних формул становить декілька відсотків. Основною перевагою запропонованого способу $\epsilon$ простота реалізації та відсутність потреби будувати аналітичний розв'язок нелінійного диференціального рівняння руху осцилятора, спричиненого початковим відхиленням його від положення статичної рівноваги. Крім того запропонований наближений спосіб розрахунку дає можливість враховувати дію різних сил опору, тобто в'язке або сухе тертя.
\end{abstract}

Ключові слова: амплітуди коливань, дисипативний осцилятор, мала нелінійність пружності, наближений спосіб, вільні коливання, різні види опору.

Вступ. Незважаючи на значні досягнення в теорії нелінійних механічних коливань продовжує інтенсивно розвиватись ця область механіки. Свідченням тому $€$ монографічні видання останніх років [1-4], що містять довгі списки літературних джерел. Причина такого розвитку зумовлена технічним прогресом, який ставить нові наукові задачі і в теорії нелінійних коливань.

Аналіз літературних даних та постановка проблеми. Вільні затухаючі коливання в умовах спільної дії сил опру різної природи висвітлено в $[5,6]$. Там розглядали коливання систем з лінійною пружністю. Значно менше публікацій стосується нелінійно пружних дисипативних систем. Дослідженням їх руху в [7-9] пов'язано з використанням методу енергетичного балансу, який не потребує аналітичного розв'язування диференціальних рівнянь. Таку перевагу мають і інші способи наближеного розрахунку, один з яких використано в цій статті. Використане тут рівняння обвідної, за прийнятим припущенням, відповідає першому наближенню асимптотичного методу теорії нелінійних коливань і було одержане при дослідженні вільних коливань дисипативного осцилятора Дуфффінга в [10]. Але тут додатково враховано залежність тривалостей напівциклів від змінної амплітуди коливань, що властиво нелінійним системам.

Метою статті є побудова наближених розрахункових формул для обчислення амплітуд вільних затухаючих коливань осциляторів зі слабкою степеневою нелінійністю у виразі сили пружності при дії сил опору різної природи.

Основна частина роботи. Для досягнення поставленої мети вводимо припущення, що вид рівняння обвідної графіка вільних коливань квазілінійного осцилятора такий як і в лінійного осцилятора, тобто нехтуємо впливом нелінійності. Про допустимість такого спрощення свідчить перше наближення асимптотичного методу, одержане в [10], при аналізі вільних коливань дисипативного осцилятора Дуфффінга, де рівняння обвідної не залежить від нелінійного доданку у виразі сили пружності.

Використовуючи вказані спрощення, розглянемо вільні коливання системи, які описуються диференціальним рівнянням: 


$$
m \ddot{x}+f(\dot{x})+\left(c_{1}+c_{2}|x|^{v}\right) x=0,
$$

при початкових умовах:

$$
x(0)=-a_{0} ; \dot{x}(0)=0 .
$$

В (1), (2): $m$ - маса осцилятора; $c_{1}, c_{2}$ - коефіцієнти жорсткості; $f(\dot{x})$ - сила опору; $v \geq 0$ - показник нелінійності; $x(t)$ - переміщення системи, як функція часу $t ; a_{0}$ - стартове відхилення системи; крапка над $x$ означає похідну по $t$.

1. Сухе тертя Кулона. В цьому варіанті опору $f(\dot{x})=F_{T} \operatorname{sign}(\dot{x})$ i, згідно з [10], у першому наближенні обвідна графріка коливань описується виразом:

$$
a(t)=a_{0}-\frac{2 F_{\mathrm{T}}}{\pi m \omega_{1}} t,
$$

де $F_{T}$ - сила сухого тертя; $\omega_{1}$ - осереднена кругова частота першого напівциклу.

Із (3) випливає наступна формула для обчислення розмаху $a_{i}$ в кінці $i$-го напівциклу:

$$
a_{i}=a_{0}-\frac{2 F_{\mathrm{T}}}{m \omega_{1}} \sum_{j=1}^{i} \frac{1}{\omega_{j}}, i=1,2,3, \ldots, n .
$$

Тут $\pi / \omega_{j}-$ тривалість $j$-го напівциклу з осередненою круговою частотою $\omega_{j} ; n-$ кількість розмахів до повної зупинки осцилятора.

Значення частоти $\omega_{j}$ можна наближено обчислити за формулою:

$$
\omega_{j}=\left[\frac{c_{1}}{m}+\frac{\alpha c_{2}}{m}\left(a_{j-1}-\frac{F_{\mathrm{T}}}{c_{1}+c_{2} a_{j-1}^{v}}\right)^{v}\right]^{1 / 2},
$$

в якій $a_{j-1}-$ амплітудне відхилення на початку $j$ го розмаху, множник

$$
\alpha=\frac{2}{\sqrt{\pi}} \frac{\Gamma\left(\frac{v+3}{2}\right)}{\Gamma\left(\frac{v+4}{2}\right)},
$$

$\Gamma(z)$ - гама-фрункція, затабульована в [11].

Якщо в (5), при $\dot{x}(t)=0$, виконується нерівність $\left(c_{1}+c_{2} a_{j-1}^{v}\right) a_{j-1} \leq F_{T}$, то осцилятор припинить рух, потрапивши в область застою.

Щоб з'ясувати похибки розрахунку характеристик коливань за фрормулами (4), (5), розглянемо приклад.

Для обчислень приймаємо: $v=1,5 ; m=2$ кг; $c_{1}=800 \mathrm{H} / \mathrm{m} ; \quad c_{2}= \pm 18000 \mathrm{Hm}^{2,5} ; \quad F_{T}=4 \mathrm{H}$; $a_{0}=0,05 \mathrm{M}$.

При цих ввідних даних [11]:

$$
\begin{gathered}
\Gamma\left(\frac{v+3}{2}\right) \approx 1,133003 ; \quad \Gamma\left(\frac{\nu+4}{2}\right) \approx 1,608359 ; \\
\alpha \approx 0,794883 .
\end{gathered}
$$

Обчислені значення розмахів $a_{i}$ та час їх досягнення $t_{i}$ записано в табл. 1 . і табл. 2.
Таблиця 1. Значення $a_{i}, t_{i}$ при $c_{2}>0$

\begin{tabular}{|c|c|c|c|c|}
\hline \multirow{2}{*}{$i$} & \multicolumn{2}{|c|}{ формули (4), (5) } & \multicolumn{2}{c|}{$\begin{array}{c}\text { чисельне } \\
\text { інтегрування (1) }\end{array}$} \\
\cline { 2 - 5 } & $100 a_{i}, \mathrm{м}$ & $t_{i}, \mathrm{c}$ & $100 a_{i}, \mathrm{~m}$ & $t_{i}, \mathrm{c}$ \\
\hline 1 & 4,15 & 0,1448 & 4,18 & 0,1447 \\
\hline 2 & 3,28 & 0,2926 & 3,32 & 0,2922 \\
\hline 3 & 2,40 & 0,4434 & 2,42 & 0,4425 \\
\hline 4 & 1,50 & 0,5968 & 1,48 & 0,5954 \\
\hline 5 & 0,58 & 0,7525 & 0,51 & 0,7503 \\
\hline
\end{tabular}

Таблиця 2. Значення $a_{i}, t_{i}$ при $c_{2}<0$

\begin{tabular}{|c|c|c|c|c|}
\hline \multirow{2}{*}{$i$} & \multicolumn{2}{|c|}{ формули (4), (5) } & \multicolumn{2}{c|}{$\begin{array}{c}\text { чисельне } \\
\text { інтегрування (1) }\end{array}$} \\
\cline { 2 - 5 } & $100 a_{i}, \mathrm{M}$ & $t_{i}, \mathrm{c}$ & $100 a_{i}, \mathrm{M}$ & $t_{i}, \mathrm{c}$ \\
\hline 1 & 3,81 & 0,1715 & 3,74 & 0,1728 \\
\hline 2 & 2,66 & 0,3373 & 2,59 & 0,3394 \\
\hline 3 & 1,53 & 0,4989 & 1,51 & 0,5016 \\
\hline 4 & 0,43 & 0,6574 & 0,49 & 0,6617 \\
\hline
\end{tabular}

Маємо задовільну узгодженість наближених результатів з умовно точними, які отримано чисельним інтегруванням задачі Коші, поданої виразами (1), (2). При $c_{2}<0$ похибка наближених формул (4), (5) дещо більша, ніж при $c_{2}>0$. У випадку м'якої характеристики пружності маємо меншу кількість розмахів до повної зупинки осцилятора, ніж при жорсткій характеристиці, що відповідає фрізичним уявленням, бо в другому випадку системі надана менша початкова потенціальна енергія. Графіки коливань на рис. 1, одержані чисельним інтегруванням рівняння (1), підтверджують цей висновок.

2. Лінійний в'язкий опір. У цьому випадку $f(\dot{x})=k_{1} \dot{x}$, де $k_{1}$ - коефіцієнт в'язкого опору. Згідно з першим наближенням в $[1,12]$ рівняння обвідної графіка коливань має вигляд:

$$
a(t)=a_{0} \exp \left(-\frac{k_{1}}{2 m} t\right) .
$$

Воно не залежить від пружності системи.

Тоді обчислення амплітуд розмахів можна провести наближено за формулою:

$$
a_{i}=a_{0} \exp \left(-\frac{\pi k_{1}}{2 m} \sum_{j=1}^{i} \frac{1}{\omega_{j}^{*}}\right)
$$

в якій:

$$
\omega_{j}^{*}=\left\{\begin{array}{l}
\frac{c_{1}}{m}-\left(\frac{k_{1}}{2 m}\right)^{2}+\frac{\alpha c_{2}}{2^{v} m} a_{j-1}^{v} \times \\
\times\left[1+\exp \left(-\frac{k_{1} \pi}{2 \sqrt{m c_{1}}}\right)\right]^{v}
\end{array}\right\}^{1 / 2}
$$




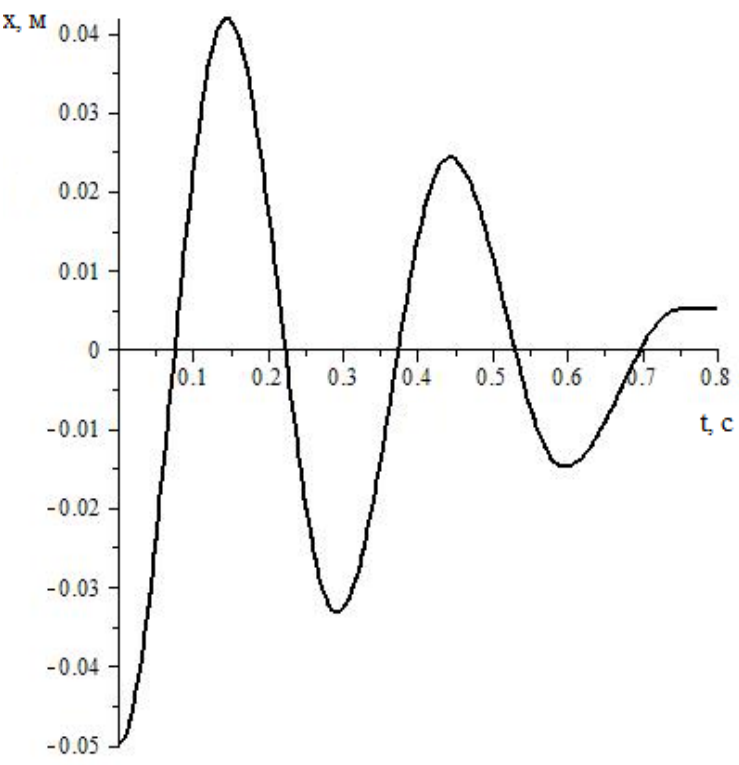

a)

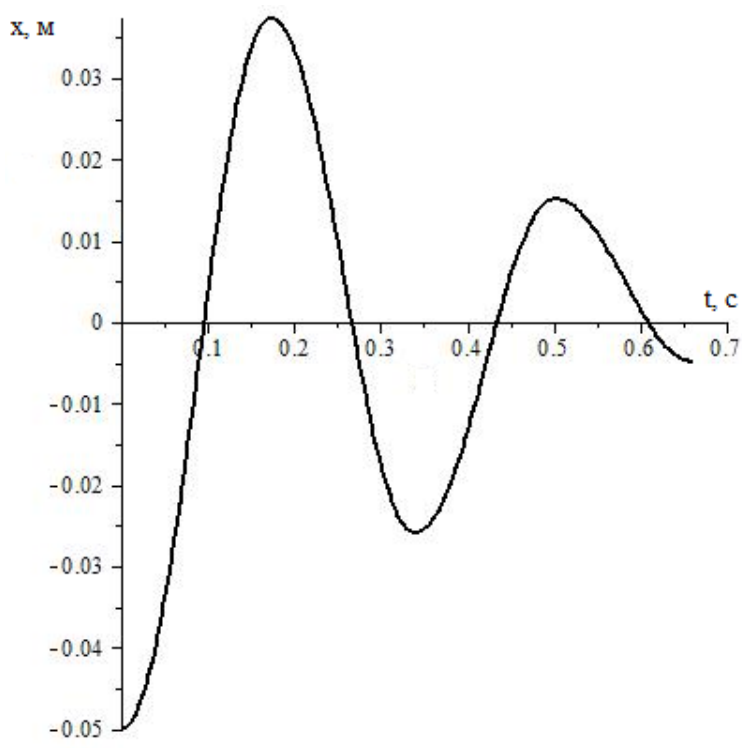

б)

Рис.1. Графіки вільних коливань:

$$
\text { а) }-c_{2}>0 \text {; б) }-c_{2}<0
$$

Розглянемо приклад.

Вхідними даними приймаємо: $v=0,8 ; m=$ $2 \mathrm{\kappa г;} c_{1}=800 \mathrm{H} / \mathrm{м} ; c_{2}= \pm 2200 \mathrm{Hм}^{-1,8} ; k_{1}=8 \mathrm{Hc} / \mathrm{м}$; $a_{0}=0,05$ м. Для них:

$$
\begin{gathered}
\Gamma\left(\frac{v+3}{2}\right) \approx 0,961766 ; \quad \Gamma\left(\frac{v+4}{2}\right) \approx 1,242169 ; \\
\alpha \approx 0,873662 .
\end{gathered}
$$

Результати обчислень шести амплітуд розмахів і часу їх досягнення записано в табл. 3 i табл. 4. Там же наведено результати чисельного інтегрування задачі Коші.
Таблиця 3. Значення $a_{i}, t_{i}$ при $k_{1}=8 \mathrm{Hc} / \mathrm{M}, c_{2}>0$

\begin{tabular}{|c|c|c|c|c|}
\hline \multirow{2}{*}{$i$} & \multicolumn{2}{|c|}{ формули (6), (7) } & \multicolumn{2}{c|}{$\begin{array}{c}\text { чисельне інте- } \\
\text { грування (1) }\end{array}$} \\
\cline { 2 - 5 } & $100 a_{i}, \mathrm{M}$ & $t_{i}, \mathrm{c}$ & $100 a_{i}, \mathrm{M}$ & $t_{i}, \mathrm{c}$ \\
\hline 1 & 3,75 & 0,1443 & 3,78 & 0,1441 \\
\hline 2 & 2,79 & 0,2911 & 2,84 & 0,2907 \\
\hline 3 & 2,07 & 0,4401 & 2,12 & 0,4395 \\
\hline 4 & 1,54 & 0,5908 & 1,58 & 0,5900 \\
\hline 5 & 1,13 & 0,7430 & 1,17 & 0,7419 \\
\hline 6 & 0,83 & 0,8963 & 0,86 & 0,8951 \\
\hline
\end{tabular}

Таблиця 4. Значення $a_{i}, t_{i}$ при $k_{1}=8 \mathrm{Hc} / \mathrm{M}, c_{2}<0$

\begin{tabular}{|c|c|c|c|c|}
\hline \multirow{2}{*}{$i$} & \multicolumn{2}{|c|}{ формули (6), (7) } & \multicolumn{2}{c|}{$\begin{array}{c}\text { чисельне інте- } \\
\text { грування (1) }\end{array}$} \\
\cline { 2 - 5 } & $100 a_{i}, \mathrm{M}$ & $t_{i}, \mathrm{c}$ & $100 a_{i}, \mathrm{M}$ & $t_{i}, \mathrm{c}$ \\
\hline 1 & 3,52 & 0,1762 & 3,46 & 0,1761 \\
\hline 2 & 2,50 & 0,3472 & 2,44 & 0,3470 \\
\hline 3 & 1,79 & 0,5148 & 1,73 & 0,5145 \\
\hline 4 & 1,28 & 0,6800 & 1,24 & 0,6795 \\
\hline 5 & 0,93 & 0,8434 & 0,89 & 0,8427 \\
\hline 6 & 0,67 & 1,0054 & 0,64 & 1,0047 \\
\hline
\end{tabular}

В табл. 3 і табл. 4 теж не спостерігається суттєвих розбіжностей наближених і точних результатів.

3. Квадратичний в'язкий опір. У цьому випадку $f(\dot{x})=k_{2} \dot{x}^{2} \operatorname{sign}(\dot{x})$, де $k_{2}-$ коефріцієнт опору. Обвідна графіка коливань у першому наближенні описується виразом [10]:

$$
a(t)=\frac{a_{0}}{1+\frac{4 a_{0}}{3 \pi} \cdot \frac{k_{2}}{m} \sqrt{\frac{c_{1}}{m}} t} .
$$

Тоді обчислення амплітуд коливань можна наближено провести за формулою:

$$
a_{i}=\frac{a_{0}}{1+\frac{4 a_{0}}{3} \cdot \frac{k_{2}}{m} \sqrt{\frac{c_{1}}{m} \sum_{j=1}^{i} \frac{1}{\omega_{j *}}},}
$$

де

$$
\omega_{j *}=\left[\frac{c_{1}}{m}+\frac{\alpha c_{2}}{m} a_{j-1}^{v}\left(\frac{1+\frac{2}{3} \frac{k_{2}}{m} a_{j-1}}{1+\frac{4}{3} \frac{k_{2}}{m} a_{j-1}}\right)\right]^{v} ;
$$

$t_{j}=\pi / \omega_{j *}-$ тривалість $j$-го розмаху.

Приклад. Обчислимо розмахи осцилятора, у якого: $v=1,8 ; m=2$ кг; $c_{1}=800 \mathrm{H} / \mathrm{M} ; c_{2}= \pm 46000$ $\mathrm{Hм}^{-2,8} ; k_{2}=6 \mathrm{Hc}^{2} / \mathrm{M}^{2}$. Для прийнятих числових даних:

$$
\begin{gathered}
\Gamma\left(\frac{v+3}{2}\right) \approx 1,242169 ; \quad \Gamma\left(\frac{v+4}{2}\right) \approx 1,827355 \\
\alpha \approx 0,767031 .
\end{gathered}
$$


Обчислені за формулами (8) і (9) значення шести розмахів і час їх досягнення записано в табл. 5 і табл. 6.

Таблиця 5. Значення $a_{i}, t_{i}$ при $k_{2}=6 \mathrm{Hc}^{2} / \mathrm{M}^{2}, c_{2}>0$

\begin{tabular}{|c|c|c|c|c|}
\hline \multirow{2}{*}{$i$} & \multicolumn{2}{|c|}{ формули (8), (9) } & \multicolumn{2}{c|}{$\begin{array}{c}\text { чисельне інте- } \\
\text { грування (1) }\end{array}$} \\
\cline { 2 - 5 } & $100 a_{i}, \mathrm{M}$ & $t_{i}, \mathrm{c}$ & $100 a_{i}, \mathrm{M}$ & $t_{i}, \mathrm{c}$ \\
\hline 1 & 4,22 & 0,1451 & 4,21 & 0,1455 \\
\hline 2 & 3,64 & 0,2929 & 3,63 & 0,2936 \\
\hline 3 & 3,20 & 0,4426 & 3,19 & 0,4436 \\
\hline 4 & 2,85 & 0,5937 & 2,84 & 0,5949 \\
\hline 5 & 2,56 & 0,7459 & 2,56 & 0,7472 \\
\hline 6 & 2,33 & 0,8988 & 2,32 & 0,9002 \\
\hline
\end{tabular}

Таблиця 6. Значення $a_{i}, t_{i}$ при $k_{2}=6 \mathrm{Hc}^{2} / \mathrm{M}^{2}, c_{2}<0$

\begin{tabular}{|c|c|c|c|c|}
\hline \multirow{2}{*}{$i$} & \multicolumn{2}{|c|}{ формули (8), (9) } & \multicolumn{2}{c|}{$\begin{array}{c}\text { чисельне інте- } \\
\text { грування (1) }\end{array}$} \\
\cline { 2 - 5 } & $100 a_{i}, \mathrm{M}$ & $t_{i}, \mathrm{c}$ & $100 a_{i}, \mathrm{M}$ & $t_{i}, \mathrm{c}$ \\
\hline 1 & 4,10 & 0,1726 & 4,09 & 0,1733 \\
\hline 2 & 3,49 & 0,3403 & 3,48 & 0,3414 \\
\hline 3 & 3,04 & 0,5053 & 3,04 & 0,5067 \\
\hline 4 & 2,70 & 0,6686 & 2,69 & 0,6701 \\
\hline 5 & 2,43 & 0,8307 & 2,42 & 0,8323 \\
\hline 6 & 2,21 & 0,9919 & 2,21 & 0,9937 \\
\hline
\end{tabular}

Тут наближені результати близькі до результатів, одержаних чисельним інтегруванням задачі Коші в середовищі Maple [13].

Висновки. Дослідження показало, що при виконанні нерівності $c_{2} a_{0}^{v} \leq 0,25 c_{1}$ наближене обчислення розмахів квазілінійного дисипативного осцилятора, при його вільних коливаннях, з похибкою в декілька відсотків, можна проводити за виведеними формулами, без побудови аналітичного розв'язку нелінійного диференціального рівняння руху осцилятора. При цьому є можливість враховувати дію різних сил опору, тобто в'язке або сухе тертя.

\section{Література}

1. Аврамов К.В. Нелинейная динамика упругих систем. Модели, методы, явления в 2 т. / К.В. Аврамов, Ю.В. Михлин. - Москва-Ижевск : Институт компьютерных исследований, 2015. T1 - $716 \mathrm{c}$.

2. Пукач П.Я. Якісні методи дослідження нелінійних коливальних систем / П.Я. Пукач. - Львів : Львівська політехніка, 2014. - 288 с.

3. Митропольский Ю.А. Избранные труды: в 2 т. / Ю.А. Митропольский. - Киев: Накова думка, 2012. - 504 c.

4. Шатохин В.М. Анализ и параметрический синтез нелинейных силовых передач машин / В.М. Шатохин. - Харьков: НТУ «ХПИ», 2008. -456 c.
5. Ольшанський В.П. Коливання дисипативних осциляторів. / В.П. Ольшанський, Л.М. Тіщенко, С.В. Ольшанський та ін. - Харків: Міськдрук, 2015. - $116 \mathrm{c}$.

6. Ольшанський В.П. Динаміка дисипативних осциляторів. / В.П. Ольшанський, Л.М. Тіщенко, С.В. Ольшанський. - Харків: Міськдрук, 2016. -264 c.

7. Ольшанський В. П. Про затухання вільних коливань дисипативного осцилятора Дуффінга / В. П. Ольшанський, В. В. Бурлака, М.В.Сліпченко. // Вісник Харківського національного технічного університету сільського господарства імені Петра Василенка: Проблеми надійності машин та засобів сільськогосподарського виробництва. Харків: ХНТУСГ, 2019. - Вип. 205. - С. 55-64.

8. Ольшанський В. П. До розрахунку вільних коливань дисипативного осцилятора з нелінійною пружністю / В. П. Ольшанський. // Вісник НТУ «ХПІ». Серія: Динаміка і міцність машин, 2019. № 2. - С. 48-52.

9. Ольшанський В. П. Про можливість застою нелінійно пружного осцилятора 3 лінійним в'язким опором / В. П. Ольшанський, С. В. Ольшанський // Вібрації в техніці та технологіях : Всеукраїнський науково-технічний журнал. - Вінниця, 2019. - № 4 (95). - С. 36-44.

10. Боголюбов Н. Н. Асимптотические методы в теории нелинейных колебаний / Н. Н. Боголюбов, Ю. А. Митропольский. - М. : Наука, 1974. - 504 c.

11. Абрамовиц М. Справочник по специальным функциям (с формулами, графиками и математическими таблицами) / М. Абрамовиц, И. Стиган. - Москва : Наука, 1979. - 832 с.

12. Василенко М. В. Теорія коливань і стійкості руху / М. В. Василенко, О. М. Алексейчук. Київ.: Вища школа, 2004. - 525 с.

13. Дьяконов В. П. Maple в математике, фризике и образовании / В. П. Дьяконов. - М. : Солонпресс, 2003. - 656 с.

\section{References}

1. Shatokhin V. M. (2008). Analiz i parametricheskij sintez nelinejnyh silovyh peredach mashin. Kharkov : NTU KhPI, 456.

2. Mitropolskij Yu. A. (2012). Izbrannye trudy: v 2 t. Kiev : Nakova dumka, 504

3. Pukach P. Ya. (2014). Yakisni metody doslidzhennya nelinijnyx kolyvalnyx system. Lviv : Lvivska politexnika, 288.

4. Avramov K. V., Mikhmen Yu. V. (2015). Nelinejnaya dinamika uprugikh sistem. Modeli, metody', yavleniya v 2 t. T1. Moskva-Izhevsk : Institut kompyuternyh issledovanij, 716.

5. Olshanskiy V.P., Tishhenko L.M., Olshanskiy S.V. and other. (2015). Kolyvannya dysypatyvnyh oscylyatoriv. Kharkiv : Mis `kdruk, 116. 
6. Olshanskiy V.P., Tishhenko L.M., Olshanskiy S.V. (2016). Dynamika dysypatyvnyh oscylyatoriv. Kharkiv: Miskdruk, 264.

7. Olshanskiy V.P., Burlaka V.V., Slipchenko M.V. (2019). Pro zatuxannya vilnyh kolyvan dysypatyvnogo oscylyatora Duffinga. Visnyk Kharkivskogo nacionalnogo tehnichnogo universytetu silskogo gospodarstva imeni Petra Vasylenka: Problemy nadijnosti mashyn ta zasobiv sils kogospodarskogo vyrobnycztva, Vol. 205, 55-64.

8. Olshanskiy V. P. (2019). Do rozraxunku vilnyx kolyvan dysypatyvnogo oscylyatora z nelinijnoyu pruzhnistyu. Visnyk NTU KhPl. Seriya: Dynamika $i$ micznist mashyn, 2, 48-52.
9. Olshanskiy V. P., Olshanskiy S. V. (2019). Pro mozhlyvist zastoyu nelinijno pruzhnogo oscylyatora $z$ linijnym vyazkym oporom. Vibraciyi $v$ texnici ta texnologiyax : Vseukrayinskyj naukovo-tehnichnyj zhurnal. Vinnycya, 4 (95), 36-44.

10. Bogolyubov N. N., Mitropol'skij Yu. A. (1974). Asimptoticheskie metody $v$ teorii nelinejnyh kolebanij. - Moskow : Nauka, 504.

11. Abramovicz M., Stigan I. (1979). Spravochnik po speczial'ny'm funkcziyam (s formulami, grafikami i matematicheskimi tabliczami). Moskow : Nauka, 832.

12. Vasylenko M. V., Aleksejchuk O. M. (2004). Teoriya kolyvan i stijkosti ruhu. Kyiv : Vyshha shkola, 525.

13. Dyakonov V. P. (2003). Maple v matematike, fizike i obrazovanii. Moskow. : Solon-press, 656.

\title{
Аннотация Приближенный метод расчета размахов свободных
колебаний квазилинейного диспипативного осциллятора
}

\author{
В.П. Ольшанский, А.И. Спольник, В.В. Бурлака, М.В. Слипченко
}

Изложен упрощенный способ приближенного вычисления размахов свободных затухающих колебаний осциллятора со слабой степенной нелинейностью в выражении силы упругости. В основу предлагаемого способа положено предположение, что нелинейное слагаемое в выражении силы упругости мало влияет на уравнение огибающей графика свободных колебаний. Использованное здесь уравнение огибающей, согласно принятому предположению, соответствует первому приближению асимптотического метода теории нелинейных колебаний и было получено при исследовании свободных колебаний диссипативного осциллятора Дуффинга в работах других авторов. Но здесь дополнительно учтено зависимость длительностей полуцикла от изменяющейся амплитуды колебаний, что свойственно нелинейным системам. По выведенными формулами проведены расчеты размахов колебаний в условиях действия различных сил сопротивления, а именно: сухого трения Кулона, линейного вязкого трения и квадратичного вязкого сопротивления. Рассмотрены различные варианты степенных нелинейностей, которые дополняют линейную составляющую в выражении силы упругости. С целью выяснения ошибок приближенного способа, проведено численное компьютерное интегрирования диффееренциального уравнения движения при различных видах сопротивления. По итогам сравнения числовых результатов, полученных различными способами, установлены ограничения на нелинейность силы упругости, в этом случае погрешности приближенных компактных формул составляет несколько процентов. Основным преимуществом предлагаемого способа является простота реализации и отсутствие необходимости строить аналитическое решение нелинейного дифференциального уравнения движения осциллятора, вызванного начальным отклонением его от положения статического равновесия. Кроме того, предложенный приближенный способ расчета позволяет учитывать действие различных сил сопротивления, то есть вязкое или сухое трение.

Ключевые слова: амплитуды колебаний, диссипативный осциллятор, малая нелинейность упругости, приближенный способ, свободные колебания, различные виды сопротивления.

\section{Abstract \\ Approximate method for calculating the ranges of free vibrations of a quasilinear dispipative oscillator}

\section{V.P. Olshanskiy, O.I. Spolnik, V.V. Burlaka, M.V. Slipchenko}

A simplified method for the approximate calculation of the ranges of free damped oscillations of an oscillator with weak power nonlinearity in the expression of the elastic force is presented. The proposed method is based on the assumption that the nonlinear term in the expression of the elastic force has little effect on the equation of the envelope of the graph of free vibrations. The envelope equation used here, according to the accepted assumption, corresponds to the first approximation of the asymptotic method of the theory of 
nonlinear oscillations and was obtained by studying the free oscillations of a dissipative Duffing oscillator in the works of other authors. But here, the dependence of the half-cycle durations on the changing oscillation amplitude, which is characteristic of nonlinear systems, is additionally taken into account. Using the derived formulas, the ranges of oscillations were calculated under the action of various resistance forces, namely, Coulomb dry friction, linear viscous friction and quadratic viscous resistance. Various versions of power nonlinearities that complement the linear component in the expression of the elastic force are considered. In order to clarify the errors of the approximate method, computer numerical integration of the differential equation of motion for various types of resistance was carried out. Based on the results of comparing the numerical results obtained in various ways, restrictions on the nonlinearity of the elastic force were established, in this case, the errors of approximate compact formulas is several percent. The main advantage of the proposed method is the simplicity of implementation and the absence of the need to build an analytical solution of the nonlinear differential equation of motion of the oscillator caused by its initial deviation from the position of static equilibrium. In addition, the proposed approximate calculation method allows you to take into account the effect of various resistance forces, that is, viscous or dry friction.

Keywords: vibration amplitudes, dissipative oscillator, small nonlinearity of elasticity, approximate method, free vibrations, various types of resistance.

\section{Бібліографрічне посилання/ Bibliography citation: Harvard}

Olshanskiy, V. P. et al. (2020) 'Approximate method for calculating the ranges of free vibrations of a quasilinear dispipative oscillator', Engineering of nature management, (1(15)), pp. 93 - 98.

Подано до редакції / Received: 02.08.2020 